\title{
Cordycepin induces Bax-dependent apoptosis in colorectal cancer cells
}

\author{
SHANG-ZE LI ${ }^{1 *}$, JIAN-WEI REN $^{2 *}$, JING FEI $^{3}$, XIAO-DONG ZHANG ${ }^{3}$ and RUN-LEI DU ${ }^{3}$ \\ ${ }^{1}$ Medical Science Research Center, Zhongnan Hospital of Wuhan University, Wuhan, Hubei 430071; \\ ${ }^{2}$ Tibet University Medical College, Lhasa, Tibet 850000; ${ }^{3}$ Hubei Key Laboratory of Cell Homeostasis, \\ College of Life Sciences, Wuhan University, Wuhan, Hubei 430072, P.R. China
}

Received January 25, 2018; Accepted October 25, 2018

DOI: $10.3892 / \mathrm{mmr} .2018 .9717$

\begin{abstract}
Cordycepin, or 3'-deoxyadenosine, is a derivative of the nucleoside adenosine. Initially extracted from the fungus Cordyceps militaris, cordycepin exhibits antitumor activity against certain cancer cell lines; however, the mechanism by which cordycepin counteracts colorectal cancer (CRC) remains poorly understood. The aim of the present study was to explore the underlying mechanisms of cordycepin against human CRC. To investigate the molecular mechanisms of cordycepin against colon cancer and in driving apoptosis, p53 and Bcl-2-like protein 4-null $\left(\mathrm{Bax}^{-/-}\right)$colon cancer HCT116 cell lines were used. Cell viability and growth were repressed in a dose-dependent manner in cells treated with cordycepin. Treatment with cordycepin resulted in increased apoptosis in HCT116 cells; however, flow cytometic analysis demonstrated that apoptosis was notably decreased in the $\mathrm{Bax}^{-/-} \mathrm{HCT} 116$ cell lines, but not in the $p 53^{-/-}$HCT116 cell lines. Furthermore, cordycepin exposure resulted in the translocation of Bax from the cytosol to the mitochondria and the subsequent release of cytochrome $c$ from the mitochondria. Results from the present study demonstrated that cordycepin inhibited colon cancer cell growth in vitro and this appears to be through the endogenous Bax-dependent mitochondrial apoptosis pathway, which suggested a molecular mechanism for cordycepin against human colon cancer. These results indicated the possibility of cordycepin as a novel drug for the prevention of colon cancer.
\end{abstract}

Correspondence to: Dr Run-Lei Du, Hubei Key Laboratory of Cell Homeostasis, College of Life Sciences, Wuhan University, 2999 Bayi Hu Road, Wuhan, Hubei 430072, P.R. China

E-mail: runleidu@whu.edu.cn

Dr Shang-Ze Li, Medicine Science Research Center, Zhongnan Hospital of Wuhan University, 169 Donghu Road, Wuchang, Wuhan, Hubei 430071, P.R. China

E-mail: shangze.li@whu.edu.cn

\section{*Contributed equally}

Key words: cordycepin, antitumor activity, colon cancer, apoptosis, Bcl-2-like protein 4, p53

\section{Introduction}

With the growth and aging of the population and the increasing number of risk factors in the lives of individuals, including smoking and heavy drinking, the incidence of cancer continues to increase annually. According to GLOBOCAN estimates, 18.1 million individuals were diagnosed with cancer and 9.6 million individuals succumbed to cancer in 2018 worldwide (1). Among all cancer-related mortalities, colorectal cancer (CRC) ranks third in both males and females (2). Although CRC mortality is declining overall, its incidence has increased in America among adults $<55$ years old, between 1970 and 2014 (3). It is well known that tumor cells exist in a state of uncontrolled growth and invasion. Such undisciplined cells may suffer from programmed cell death to protect organisms. Cancer development is due to the inactivation of the apoptotic pathway (4), resulting in drugs resistant of cancer cells. Previous studies have reported that resistance to drugs is occasionally due to Bax gene mutations; Bcl-2-like protein 4 $(B a x)$ is an important regulatory factor of the mitochondrial apoptosis pathway (5-8).

Apoptosis is one mechanism by which cell death occurs. p53 is a tumor-suppression gene that serves an important role in apoptosis, cell aging and cell cycle arrest (9). The inactivation of p53 in the p53-dependent apoptosis pathway may promote tumor occurrence, tumor development and resistance to antitumor drugs (10). The $B c l-2$ gene family serves important functions in the intrinsic mitochondrial-mediated apoptosis pathway. In this family, certain members exhibit inhibitory effects on apoptosis, whereas others such as Bax promote apoptosis (11). Bax is normally located in the cytoplasm; once the apoptotic signal is received, Bax undergoes oligomerization and is translocated to the mitochondrial membrane, which subsequently leads to the release of cytochrome $c$ and other apoptosis factors into the cytoplasm $(12,13)$. Cytochrome c combines apoptotic protease activating factor-1 and pro-caspase-9, which form apoptosomes, which lead to the activation of caspase-9 and caspase-3. Previous studies have reported that Bax deficiency may cause cancer cells to become insensitive to certain antitumor drugs by preventing the translocation of Bax to the mitochondria (14).

Cordycepin (3' deoxyadenosine), a derivative of the nucleoside adenosine, is a metabolic product extracted from 
Cordyceps militaris (15) and is a major bioactive component with important anticancer potential (16). Previous studies in several disease models have demonstrated that cordycepin possesses antitumor and anti-inflammatory effects that occur through the inhibition of mRNA synthesis $(17,18)$. Cordycepin possesses anticancer activities, including antiproliferation, autophagy promotion, anti-migration and apoptosis induction $(19,20)$. Although the anticancer activity of cordycepin has been examined in human bladder, brain and lung cancer cells, the mechanism by which cordycepin affects CRC remains poorly understood (21-23).

Results from the present study indicated that cordycepin suppresses colon cancer cell growth in vitro and demonstrated that cordycepin may accelerate apoptosis in HCT116 cells by inducing the translocation of Bax to the mitochondrial membrane (24). However, cordycepin-induced apoptosis and Bax translocation was notably inhibited in isogenic Bax-null ( $\mathrm{Bax}^{-/}$) human colon cancer HCT116 cells. Cordycepin-activated Bax translocation induced apoptosis, which was recovered through the reintroduction of Bax expression into $\mathrm{Bax}^{-/-}$cells. Taken together, these results suggested that cordycepin may establish the foundation of a therapeutic approach for cancers by targeting the Bax protein.

\section{Materials and methods}

Cell lines and plasmids. HCT116 human colorectal carcinoma cells were purchased from the American Type Culture Collection(Manassas, VA,USA). $p 53^{-/-}$, a $^{-/-}$and $p 21^{-/-}$HCT116 cells were obtained from Dr Bert Vogelstein (Johns Hopkins University, Baltimore, MD, USA). The pEGFP-C3-Bax expression vectors were provided by Dr Quan Cheng (Institute of Zoology, Chinese Academy of Sciences, Beijing, China).

Cell culture. Wild-type (WT) HCT116, HCT116-p53/-, HCT116-p $21^{-/-}$and HCT116- ax $^{-/-}$cells were cultured in McCoy's 5A Medium (cat. no. A1324-9050; AppliChem, Inc., Maryland Heights, MO, USA) with $10 \%$ (v/v) fetal bovine serum (GE Healthcare Life Sciences, Logan, UT, USA) and $100 \mathrm{U}$ penicillin/streptomycin (Gibco; Thermo Fisher Scientific, Inc., Waltham, MA, USA) at $37^{\circ} \mathrm{C}$ in a $5 \% \mathrm{CO}_{2}$ incubator.

Reagents and antibodies. Cordycepin $\left(\mathrm{C}_{10} \mathrm{H}_{13} \mathrm{~N}_{5} \mathrm{O}_{3} ; 251\right.$ Da; cat. no. C3394; Fig. 1A) and caspase-3 inhibitor (cat. no. 219007) were purchased from Sigma-Aldrich (Merck KGaA, Darmstadt, Germany). Rabbit monoclonal antibodies against Bax (cat. no. 5023), pro-caspase-3 (cat. no. 9665), cytochrome $c$ oxidase IV (CoxIV; cat. no. 4850) and cleaved poly(ADP-ribose) polymerase (PARP; cat. no. 9541) were purchased from Cell Signaling Technology, Inc. (Danvers, MA, USA). The anti-mouse monoclonal p53 antibody (cat. no. sc-126) and anti-mouse cytochrome $c$ (cat. no. sc-126) were obtained from Santa Cruz Biotechnology, Inc. (Dallas, TX, USA). The anti-mouse monoclonal $\beta$-actin antibody (cat. no. AC004) was purchased from ABclonal Biotech Co., Ltd. (Woburn, MA, USA). The anti-mouse monoclonal $\beta$-tubulin antibody (cat. no. AbM59005-37B-PU) was obtained from Beijing Protein Innovation (Beijing, China). The horseradish peroxidase (HRP)-conjugated secondary antibodies (cat. nos. 111-035-003 or 115-035-003) were obtained from Jackson ImmunoResearch Laboratories, Inc. (West Grove, PA, USA).

Transient and stable transfection. Lipofectamine ${ }^{\circledR} 2000$ (Invitrogen; Thermo Fisher Scientific, Inc.) was used for transient transfections according to the manufacturer's protocols. Transfection reagents and DNA were mixed in Opti-MEM (Invitrogen; Thermo Fisher Scientific, Inc.); For 6-well plate, $200 \mu \mathrm{l}(10 \mu \mathrm{g} / \mathrm{ml})$ transfection DNA complex was added to cells grown to $30-60 \%$ confluency, and the culture was incubated for $\sim 3 \mathrm{~h}$, and the medium was replaced with fresh full McCoy's 5A medium. For EGFP-Bax stable transfections, $0.5 \mathrm{mg} / \mathrm{ml} \mathrm{G} 418$ was added to the medium for $48 \mathrm{~h}$ following transient transfection, and the cells were selected after 2 weeks. Thereafter, stable cells were always maintained in $0.25 \mathrm{mg} / \mathrm{ml}$ G418 medium.

Colony formation and soft agar assay. Soft agar and colony formation assays were used to examine the viability and tumorigenicity of HCT116 cells following treatment with cordycepin. Briefly, $3 \times 10^{3}$ HCT116 cells were treated with various concentrations of cordycepin $(0,62.5,135,270$ and $540 \mu \mathrm{M})$ for $24 \mathrm{~h}$; the medium and drugs were subsequently replaced with fresh medium. After 2 weeks incubation, cell clones were stained with $0.05 \%$ crystal violet at room temperature for $30 \mathrm{~min}$ and images were captured by scanner (MRS-2400U2; Microtek, Shanghai, China).

For the soft agar test, $2 \mathrm{ml}$ of $0.7 \%$ lower agar-McCoy's 5A with cordycepin $(0-540 \mu \mathrm{M}$, as aforementioned) was plated onto each well of 6-well plates. Subsequently, $1 \mathrm{ml}$ of HCT116 cells $\left(1 \times 10^{4}\right)$ was mixed with $1 \mathrm{ml}$ of $0.7 \%$ agar-McCoy's 5A/cordycepin $(0-540 \mu \mathrm{M}) \mathrm{mix}$ and added to the curdled lower agar; $2 \mathrm{ml}$ of McCoy's 5A medium was added to the upper agar, and the plates were incubated at $37^{\circ} \mathrm{C}$ in a $5 \% \mathrm{CO}_{2}$ incubator for 3 weeks, and the numbers of clones were counted and images captured by an inverted microscope (ICX41; SDPTOP, Shanghai, China).

Cell viability assay. Cell viability was examined using Cell Counting Kit-8 (CCK-8; Dojindo Laboratories, Kumamoto, Japan), following the manufacturer's protocol. The HCT116 cell lines [wild-type (WT) HCT116, HCT116-p53\%, HCT $116-\mathrm{p} 21^{-/-}$and HCT116- $\mathrm{Bax}^{-/}$] aforementioned were seeded $\left(1 \times 10^{4}\right.$ cells/well) into a 96 -well plate, cultured to $60 \%$ confluency and exposed to different doses of cordycepin $(0,33.75,62.5,135,270$ and $540 \mu \mathrm{M})$ for $24 \mathrm{~h}$. The medium was replaced with $100 \mu \mathrm{l}$ of fresh McCoy's 5A full medium with $10 \%$ CCK- 8 reagent and incubated for $1 \mathrm{~h}$. Absorbance was detected at $450 \mathrm{~nm}$ using an ELx800 microplate reader (BioTek Instruments, Inc., Winooski, VT, USA). The results were expressed as percentages of cell viability.

Apoptosis assay. The HCT116 cell lines (1x104 cells/well) were seeded in 6-well plates and cultured to $60 \%$ confluency. Following exposure to the various concentration of cordycepin $(0,135$ and $270 \mu \mathrm{M})$ for $24 \mathrm{~h}$, cells were collected, washed with phosphate buffered saline (PBS) twice. Subsequently, the cells were centrifuged at $120 \mathrm{x} \mathrm{g}$ in the room temperature for $5 \mathrm{~min}$ and suspended in apoptosis binding buffer $(50 \mathrm{mM}$ 
HEPES, $700 \mathrm{mM} \mathrm{NaCl}, 12.5 \mathrm{mM} \mathrm{CaCl}_{2}, \mathrm{pH}$ 7.4) at a concentration of $1 \times 10^{6}$ cells $/ \mathrm{ml}$. Cells were stained with propidium iodide (PI) and Annexin V fluorescein isothiocyanate (FITC) for 10-15 $\mathrm{min}$ at room temperature. Samples were subjected to flow cytometry (Beckman Coulter, Fullerton, CA) and data were analyzed using FlowJo software (10.07 version). For apoptosis inhibition assay, the cells were incubated with $25 \mu \mathrm{M}$ caspase- 3 inhibitor for $24 \mathrm{~h}$ to prevent PARP cleavage and cell apoptosis.

Mitochondrial isolation. HCT116 cells $\left(5 \times 10^{6}\right)$ were exposed to $270 \mu \mathrm{M}$ cordycepin for $24 \mathrm{~h}$. The Mitochondria/Cytosol Fractionation Kit (Beyotime Institute of Biotechnology, Beijing, China) was used to isolate the mitochondrial and cytosolic proteins. Briefly, cells were resuspended in the mitochondria isolation buffer and homogenized with a $2 \mathrm{ml}$ glass homogenizer on ice. Cell lysates were centrifuged at $1,000 \mathrm{x} \mathrm{g}$ for $10 \mathrm{~min}$ at $4^{\circ} \mathrm{C}$, and the supernatant was centrifuged at $14,000 \mathrm{x}$ f for $15 \mathrm{~min}$ at $4^{\circ} \mathrm{C}$. The supernatant included the cytosolic fraction, and the pellet contained the mitochondrial fraction.

GFP-Bax translocation assay. GFP-Bax plasmids were stably expressed in $\mathrm{Bax}^{-/-}$HCT116 cells. Cells were exposed to cordycepin (0 or $270 \mu \mathrm{M})$ for $12 \mathrm{~h}$ and fixed with $4 \%$ paraformaldehyde for $30 \mathrm{~min}$ at room temperature. The fixed cells were observed using a confocal microscope using an x60 oil objective. Images were captured using 2.0b Olympus FluoView software (Olympus Corporation, Tokyo, Japan), and distribution pattern of GFP-Bax was examined.

Western blot assay. An immunoblotting assay was performed as described previously (25). Briefly, cells were cultured on 6 -well plates to $60 \%$ confluency and subsequently treated with cordycepin $(0-540 \mu \mathrm{M})$ for $24 \mathrm{~h}$. Cells were lysed with SDS sample buffer (62.5 mM Tris- $\mathrm{HCl}$ pH 6.8, 2\% SDS, $10 \%$ glycerol) at $95^{\circ} \mathrm{C}$ for $10 \mathrm{~min}$. Protein concentrations were determined using a BCA protein assay kit (Thermo Fisher Scientific, Inc.). Protein samples $(20 \mu \mathrm{g})$ were separated by $10 \%$ SDS-PAGE, transferred and incubated with indicated primary antibodies $(1: 1,000)$ overnight at $4^{\circ} \mathrm{C}$ and HRP-conjugated secondary antibodies $(1: 10,000)$ at room temperature for $1 \mathrm{~h}$. The $\beta$-actin was used as loading control. Protein expressions were visualized with the Immobilon Western Chemiluminescent HRP Substrate kit (Merck KGaA, Minneapolis, MN, USA).

Statistical analysis. All data were analyzed using SPSS software version 20.0 (IBM Corp., Armonk, NY, USA). For data with a Gaussian distribution, parametric statistical analysis was performed using the two-tailed Student's t-test for two groups; one-way analysis of variance was used for multiple comparisons followed by Bonferroni's post hoc analysis for data meeting homogeneity of variance or with Tamhane's T2 analysis for data of heteroscedasticity. For data sets with skewed distribution, non-parametric statistical analysis was performed using the Kruskal-Wallis test followed by the Dunn's test for multiple comparisons. Only in the cases in which the global null hypothesis was rejected was pairwise comparison subsequently performed. For all analyzed variables, a pre-specification approach was performed. $\mathrm{P}<0.05$ was considered to indicate a statistically significant difference.

\section{Results}

Cordycepin represses HCT116 cell growth in vitro. To determine the most suitable concentration of cordycepin to treat colon cancer cells, the half-maximal inhibitory concentration $\left(\mathrm{IC}_{50}\right)$ of cordycepin in HCT116 cells was determined. HCT116 cells were treated with $0-540 \mu \mathrm{M}$ cordycepin for $24 \mathrm{~h}$ and further cultured at $37^{\circ} \mathrm{C}$ in a $5 \% \mathrm{CO}_{2}$ incubator for $\sim 10$ days. The viability of the HCT116 cells clearly decreased following cordycepin treatment (Fig. 1B and C); and the results demonstrated that the $\mathrm{IC}_{50}$ of cordycepin was $434 \mu \mathrm{M}$ for HCT116 cells (Fig. 1B). Soft agar assays were conducted to examine the effects of cordycepin treatment on tumor formation in vitro. At 2 weeks post-treatment, anchorage-independent tumor growth was significantly inhibited in a dose-dependent manner in cells incubated with cordycepin (Fig. 1D). These results demonstrated that cordycepin has significant inhibitory effects on human HCT116 cell viability, proliferation and tumorigenesis in vitro.

Cordycepin induces apoptosis in HCT116 cells. To determine the molecular mechanism underlying the anticancer activity of cordycepin, cordycepin-activated apoptotic activity was examined in HCT116 cells. The results demonstrated that cells treated with 0,135 and $270 \mu \mathrm{M}$ cordycepin for $24 \mathrm{~h}$ exhibited average $7.8,13.4$ and $22.1 \%$ early apoptotic rates, respectively (Fig. 2A). To confirm the apoptotic phenotype, the levels of certain proteins that are closely associated with apoptosis were tested. HCT116 cells were exposed to $0-540 \mu \mathrm{M}$ cordycepin for $24 \mathrm{~h}$, and the protein expression levels of p53 and its target gene p21 were investigated by western blot analysis, which demonstrated notably higher protein expression levels in cells treated with cordycepin, and the increased expressions were in a dose-dependent manner (Fig. 2B). The apoptosis markers, pro-caspase- 3 and cleaved PARP were also analyzed by western blotting, and the results demonstrated lower pro-caspase-3 and higher cleaved PARP levels in response to increased cordycepin concentrations (Fig. 2B). These data suggested that cordycepin induced apoptosis in HCT116 cells. To further demonstrate that increased cleaved-PARP occurred through a caspase-3-dependent pathway, cells were incubated with $25 \mu \mathrm{M}$ caspase-3 inhibitor for $24 \mathrm{~h}$ to prevent cell apoptosis, and the results demonstrated that the caspase-3 inhibitor blocked cordycepin-induced cleaved-PARP expression in HCT116 (Fig. 2C). These results suggested that cordycepin may induce apoptosis in HCT116 CRC cells.

Cordycepin induces HCT116 cell death through Bax-dependent apoptosis. Bax, a pro-apoptosis Bcl-2 family member, translocates from the cytoplasm to the mitochondria in response to stimulation, which subsequently results in the release of cytochrome $c$ and cell apoptosis (26). The tumor suppressor protein p53 serves an important role in the maintenance of genomic stability and cell apoptosis $(27,28)$. To understand whether p53 or Bax serves a role in cordycepin-induced apoptosis, the apoptotic effects following cordycepin treatment in HCT116-WT, HCT116- $p 53^{-/-}$and HCT116-Bax ${ }^{-/-}$cells were examined (Fig. 3). 
A<smiles>Nc1ncnc2c1ncn2C1OC2CC1[C@@H](O)C2</smiles>

C

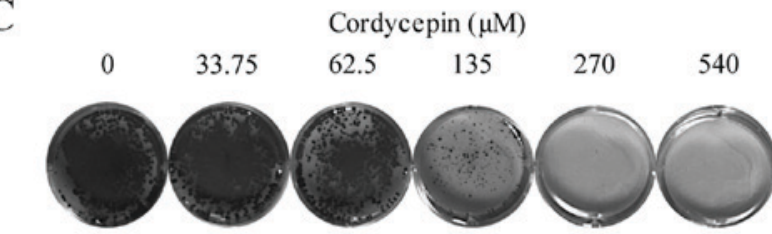

B

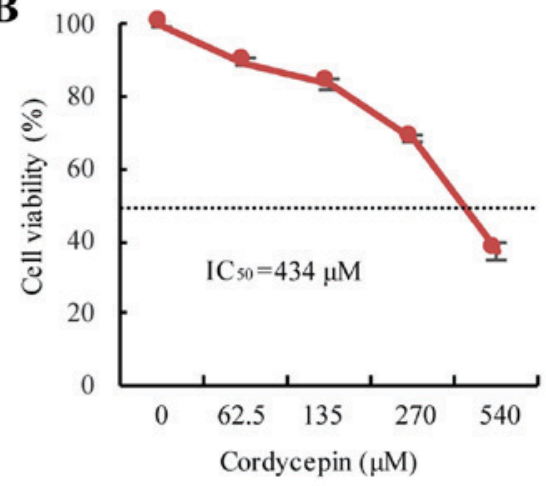

D
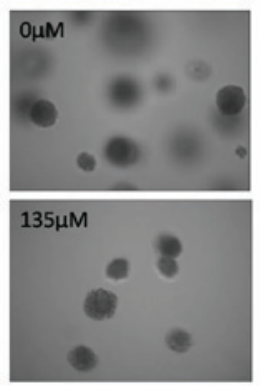

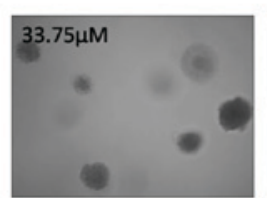

$270 \mu \mathrm{M}$
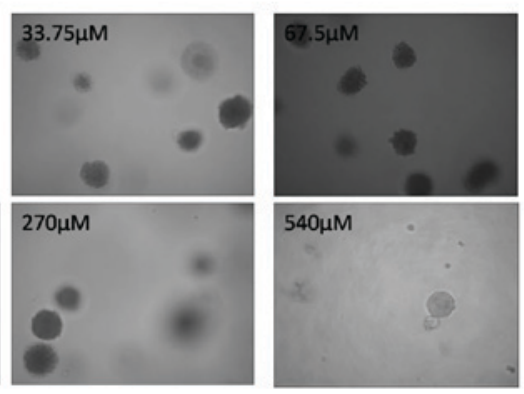

Figure 1. Cordycepin represses HCT116 cell growth in vitro. (A) Chemical structure of cordycepin. (B) Cell viability was examined with Cell Counting Kit-8 and cytotoxicity, $\mathrm{IC}_{50}$, was calculated for HCT116 cells treated with various concentrations of cordycepin $(0-540 \mu \mathrm{M})$. (C) Colony formation assay of HCT116 cells exposed to cordycepin for $24 \mathrm{~h}$; HCT116 cell clones were stained with crystal violet and images acquired. (D) Soft agar assay of HCT116 cells treated with cordycepin in $0.35 \%$ upper agar and $0.7 \%$ lower agar for 14 days. ${ }^{* * *} \mathrm{P}<0.001$ vs. Untreated control. $\mathrm{IC}_{50}$, half maximal inhibitory concentration.

HCT116 cells were treated with $0-270 \mu \mathrm{M}$ cordycepin for $24 \mathrm{~h}$ and cell viability was examined (Fig. 3A). The cell viability of HCT116 and HCT116-p53-- cells was significantly decreased with increasing cordycepin concentration; however, $\mathrm{Bax}^{-1-}$ cells treated with various concentrations appeared to be insensitive to cordycepin treatment compared with the HCT116-WT and $p 53^{--}$cells. These results indicated that Bax may serve a more essential part in cordycepin-induced cell death compared with p53. In addition, the mutant cell lines were exposed to $62.5 \mu \mathrm{M}$ cordycepin for $24 \mathrm{~h}$, cultured for an additional 10 days and the colony number reduced in HCT116-WT and HCT116- $p 53^{-1-}$ cells but not in HCT116-Bax ${ }^{-/}$cells (Fig. 3B). HCT116-WT, $\mathrm{p5}^{-/}$and $\mathrm{Bax}^{-/} \mathrm{HCT} 116$ cells were also incubated with $270 \mu \mathrm{M}$ cordycepin for $24 \mathrm{~h}$, and the Annexin V/FITC staining results demonstrated that average $2.76 \%$ of the $\mathrm{Bax}^{-1-}$ cells were early apoptotic compared with $8.03 \%$ of the HCT116-WT cells, which also suggested that $\mathrm{HCT} 116-\mathrm{Bax}^{-/}$cells were insensitive to cordycepin treatment (Fig. 3C). The reason why $p 53^{-/-}$cells are more sensitive to cordycepin treatment is that $p 53$ is an essential gene for cell life activities; thus, the amount of cell death in this line is already substantially higher than that of WT cells. Apoptosis will result in DNA fraction; therefore, we determined the DNA fraction using PI staining and the results consistent with the Annexin V/FITC staining (Fig. 3D). These results indicated that cordycepin-induced apoptosis may be Bax dependent.

Cordycepin releases cytochrome c to induce apoptosis is dependent on Bax. As aforementioned, cordycepin-induced apoptosis may be Bax-dependent. To assess whether cordycepin induces the cleavage of PARP in $p 53^{-/}$or $\mathrm{Bax}^{-/}$HCT116 cells, cleaved-PARP protein expression levels were analyzed. Cells were treated with $0-270 \mu \mathrm{M}$ cordycepin for $24 \mathrm{~h}$, and the protein expression levels of p53, Bax and cleaved-PARP were notably increased with higher concentrations of cordycepin treatment in HCT116-WT cells. Additionally, significant levels of cell apoptosis were observed in the $p 53^{--}$HCT116 cells, but apoptosis markers cleaved-PARP were blocked in the $\mathrm{Bax}^{-1-}$ HCT116 cells (Fig. 4A). The inhibition of cordycepin-induced PARP protein cleavage in the $B a x^{-/-}$HCT116 cells was rescued by reintroducing the $B a x$ gene into Bax $^{-/}$HCT116 cells (Fig. 4B). The translocation of Bax to the mitochondria may exert an important effect on apoptotic initiation (29). The stable EGFP-Bax cell line allowed for the tracking of the location of Bax protein expression. Untreated control cells exhibited a diffuse distribution of green fluorescence among 
A

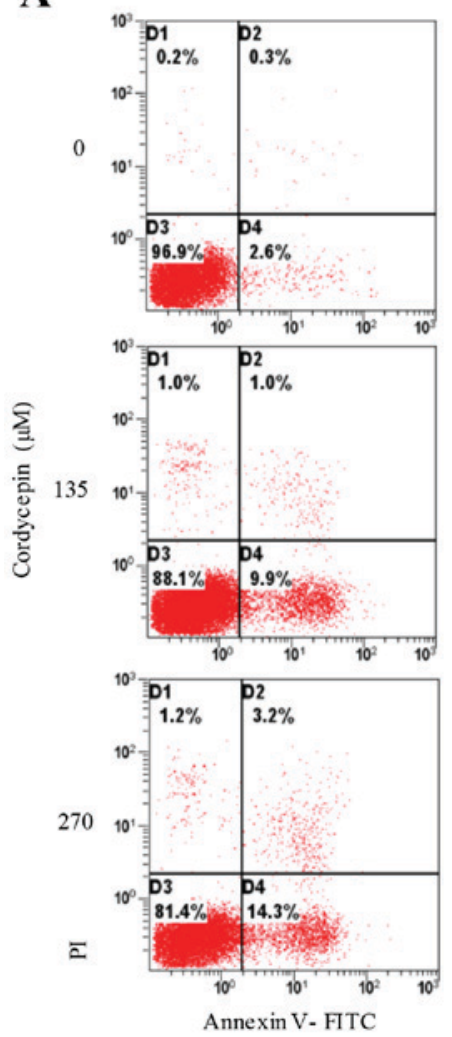

C
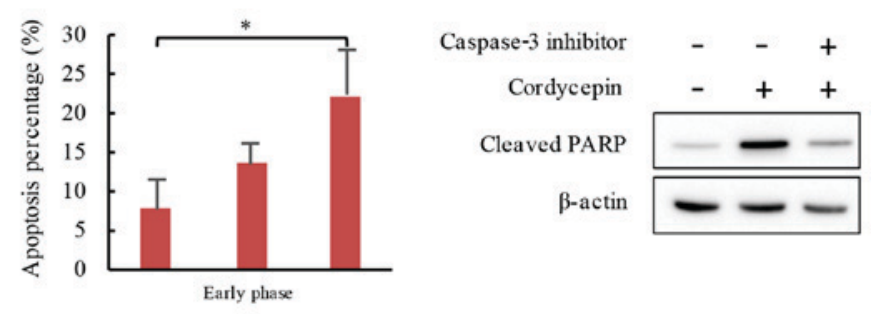

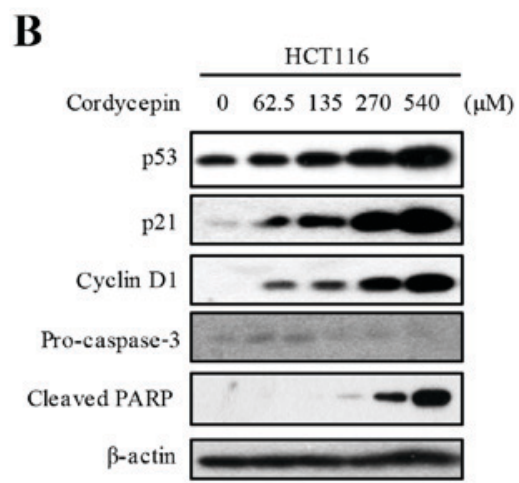

Figure 2. Cordycepin induces apoptosis in HCT116 cells. (A) Annexin V FITC- and PI-stained cells were examined by flow cytometry following exposure to cordycepin $(0,135$ or $270 \mu \mathrm{M})$. (B) p53, p21, cyclin D1, pro-caspase-3 and cleaved PARP protein expression levels were examined by western blotting in cells treated with different concentrations of cordycepin for $24 \mathrm{~h} ; \beta$-actin was used as a loading control. (C) HCT116 cells were exposed to $270 \mu \mathrm{M}$ cordycepin with or without cotreatment with a caspase-3 inhibitor, and cleaved PARP protein expression levels were detected by western blot analysis; $\beta$-actin was used as a loading control. FITC, fluorescein isothiocyanate; PARP, poly(ADP-ribose) polymerase; PI, propidium iodide.

A

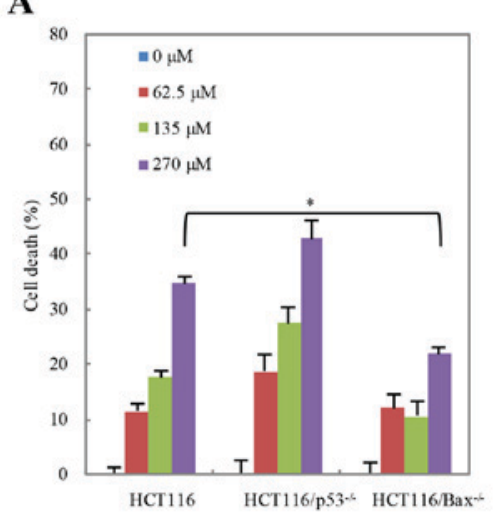

B

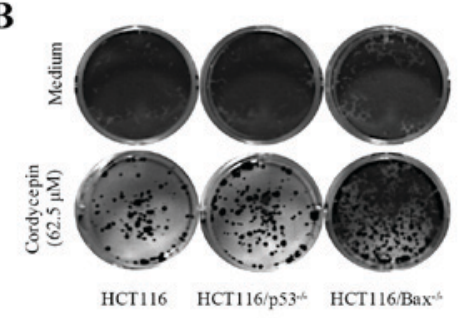

C
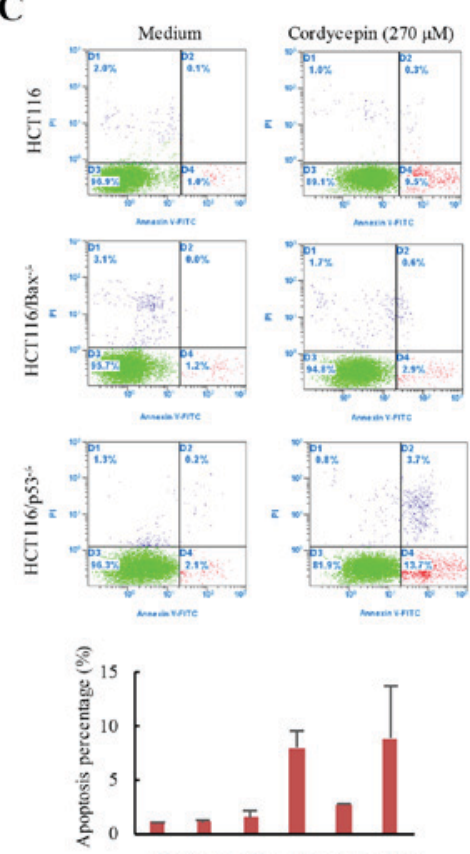

WT Bax $553^{* 6}$ WT Bax*t p53,
D
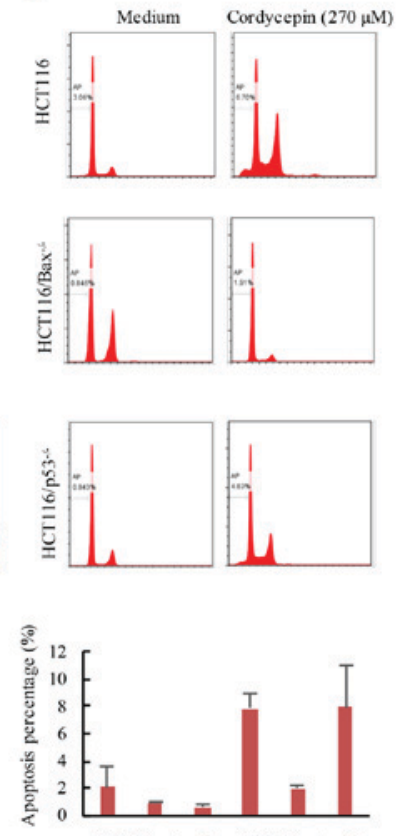

WT Bax ${ }^{\epsilon} 53^{+*}$ WT Bax ${ }^{+6} 53^{4}$

Figure 3. Cordycepin induces HCT116 cell death through Bax-dependent apoptosis. (A) Cell viability assay. HCT116, HCT116-p53 ${ }^{-/}$and HCT116-Bax ${ }^{-/}$cells were treated with 0-270 $\mu \mathrm{M}$ cordycepin; cell viability was detected by CCK-8 24 h later. (B) HCT116 cells, HCT116-p53 ${ }^{-/}$and HCT116-Bax ${ }^{-/}$cells were exposed to $62.5 \mu \mathrm{M}$ cordycepin for $24 \mathrm{~h}$, and cell clones were stained with crystal violet and images acquired. (C and D) Apoptosis assay for HCT116-WT, HCT116-p53 $3^{-/}$and HCT116-Bax ${ }^{-/}$cells exposed to 0 or $270 \mu \mathrm{M}$ cordycepin and subjected to (C) Annexin V FITC/PI flow cytometry assay and (D) PI staining. ${ }^{*} \mathrm{P}<0.05$ vs. wild-type HCT116 cells. FITC, fluorescein isothiocyanate; PI, Propidium iodide. 
$\mathbf{A}$

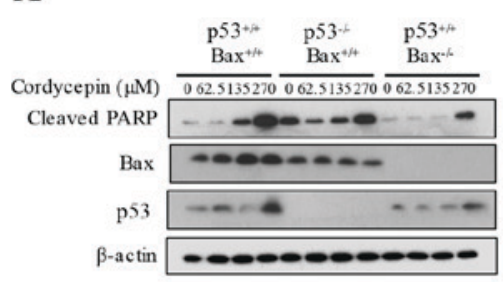

B

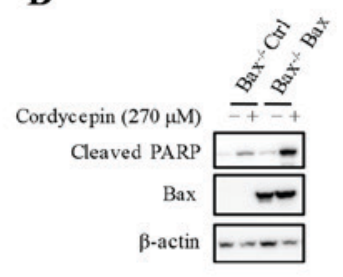

C

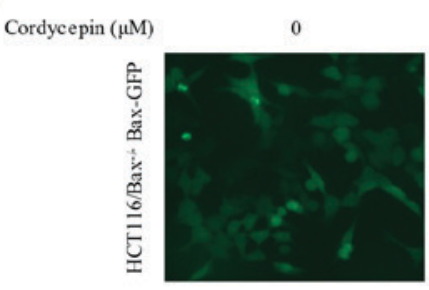

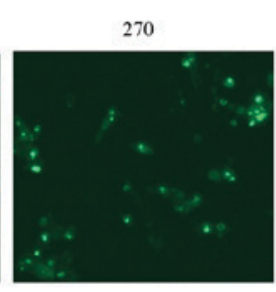

D

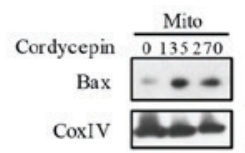

$\mathbf{E}$

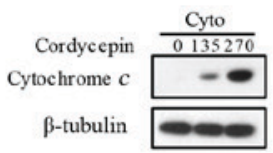

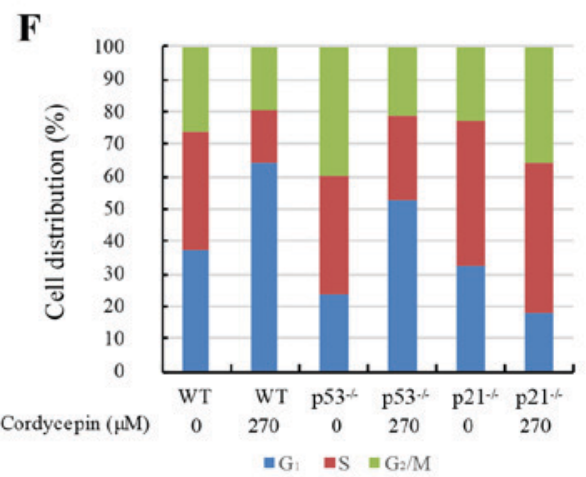

Figure 4. Cordycepin utilizes Bax releasing cytochrome $c$ to induce apoptosis. (A) Apoptosis marker protein expression levels in HCT116, HCT116-p53 $\%$ and HCT116-Bax ${ }^{-/}$cells treated with 0 or $270 \mu \mathrm{M}$ cordycepin were measured by western blotting. (B) Cordycepin-induced apoptosis is hindered in Bax ${ }^{-/}$HCT116 cells, but recovered by reintroduction of the Bax gene. (C) The EGFP-Bax plasmid is stably overexpressed in Bax ${ }^{-/}$HCT116 cells, and the cells were exposed to $270 \mu \mathrm{M}$ cordycepin for $24 \mathrm{~h}$; the location of the EGFP-Bax protein was determined using a fluorescence microscope and compared with that of untreated EGFP-Bax control cells. Magnification, x20. (D and E) HCT116 cells were exposed to $270 \mu \mathrm{M}$ cordycepin for $24 \mathrm{~h}$, and mitochondria and cytoplasm were isolated; cytochrome $c$ and Bax protein expressions were detected by western blot analysis; $\beta$-tubulin and CoxIV were used as loading controls. (F) Cordycepin arrested the cell cycle at the $\mathrm{G}_{1} / \mathrm{S}$ phase through $\mathrm{p} 21$ in the HCT116 cell line. PI staining flow cytometry was used to analyze the cell cycle profiles in HCT116, HCT116-p53 $3^{-/}$and HCT116-p2 $1^{-/}$cells treated with or without $270 \mu \mathrm{M}$ cordycepin. ${ }^{* *} \mathrm{P}<0.01 \mathrm{vs}$. the controls. Bax, Bcl-2-like protein 4 ; CoxIV, cytochrome $c$ oxidase IV; cyto, cytoplasm; GFP, green fluorescent protein; mito, mitochondria; PARP, poly(ADP-ribose) polymerase; PI, propidium iodide; WT, wild-type.

whole cells, whereas almost $70 \%$ of the cordycepin-treated cells demonstrated only punctate fluorescence, which suggested the translocation of Bax reached $70 \%$ in the cordycepin-treated cells (Fig. 4C). In addition, western blot analysis revealed increased Bax protein expression in the mitochondria when exposed to cordycepin (Fig. 4D). cytochrome $c$ is located in the mitochondrial inner membrane; its translocation from the mitochondria to the cytosol induces cell apoptosis (30). As a downstream marker of Bax aggregation, the protein levels of cytochrome $c$ in the cytoplasm of HCT116 cells exposed to cordycepin was examined. The results demonstrated increased cytochrome $c$ expression the cytosol in response to cordycepin exposure (Fig. 4E). These data demonstrated that Bax is employed in cordycepin-induced apoptosis.

Cordycepin arrests the cell cycle at the $G_{1} / S$ phase through p21 in HCT116 cells. In addition to investigating cordycepin-induced apoptosis, whether cordycepin was involved in cell cycle profile changes was examined. Flow cytometric assay results demonstrated that cordycepin treatment resulted in cell cycle arrest in the HCT116-WT cells in the $\mathrm{G}_{1} / \mathrm{S}$ phase (Fig. $4 \mathrm{~F}$ ). However, in the $p 21^{-/-}$HCT116 cells, $\mathrm{G}_{1} / \mathrm{S}$ phase arrest was reduced. Whether $p 53$, which is directly controlled by the expression of $p 21$ (31), is involved in $\mathrm{G}_{1} / \mathrm{S}$ phase arrest was also examined. As expected, in p53/-deficient HCT116 cells, $\mathrm{G}_{1} / \mathrm{S}$ phase arrest was clearly ameliorated when compare to HCT116-WT cells treated with $270 \mu \mathrm{M}$ cordycepin (Fig. 4F). As the protein expression levels of p21 and p53 were increased in response to cordycepin, it was hypothesized that cordycepin treatment may induce $\mathrm{G}_{1} / \mathrm{S}$ phase cell cycle arrest in HCT116 cells by inducing the expression of $p 53$ and its target gene $p 21$.

\section{Discussion}

The antitumor activity of cordycepin on human CRC cell growth in vitro was examined in the present study, and it was identified that its molecular mechanism may be associated with Bax-dependent apoptosis. In addition, it was demonstrated that cordycepin-induced apoptosis may be reversed by an inhibitor of caspase. Using the $\mathrm{Bax}^{-/-}$and $p 53^{-/-}$HCT116 cell lines, it was demonstrated that apoptosis induced by cordycepin was notably increased in the Bax-dependent pathway, but not in the p53-dependent pathway. The localization of Bax to the mitochondria following cordycepin treatment indicated that the Bax protein may be required for cordycepin-induced apoptosis. Notably, the reintroduction of Bax into Bax ${ }^{-/}$cells recovered the cordycepin-induced apoptosis effect.

Apoptosis is a programmed cell death process that occurs in multicellular organisms during both normal cell growth and aging. Improper apoptosis results in a variety of diseases, including CRC (32). The induction of apoptosis by antitumor drugs is mediated by a variety of mechanisms, including cell cycle and replication arrest, transcription regulation, DNA repair, apoptosis and autophagy (33). The initiation of apoptosis has extrinsic and intrinsic pathways. Mitochondria serve a pivotal role in the intrinsic pathway and are involved in drug-induced apoptosis; in addition, members of the Bcl-2 family take part in intrinsic pathway regulation, including regulation of the Bax gene (34).

To identify whether $p 53$ or Bax serves a pivotal role in cordycepin-induced apoptosis, apoptosis was examined in WT, p53/- and Bax ${ }^{-/-}$HCT116 cells in the presence or absence of cordycepin. Increased apoptosis was observed in HCT116 and p53 $^{-/-}$cells, but not in $\mathrm{Bax}^{-/-}$cells, and Bax 
was demonstrated to translocate to the mitochondria in an EGFP-Bax stable cell line treated with cordycepin. The data indicated that cordycepin-induced apoptosis may depend on Bax activity.

Cordycepin is a purine nucleoside antimetabolite and antibiotic isolated from the fungus Cordyceps militaris that has certain antineoplastic activities (35). The results of the present study are consistent with cordycepin induced apoptotic cell death, and demonstrated that cordycepin-induced apoptosis in human CRCs may be more dependent on Bax than p53. Although the present study has clarified the role and apoptotic mechanism of cordycepin in human CRC, additional studies, including investigations in an animal model, are required to determine a therapeutic strategy.

In conclusion, the results of the present study suggested that cordycepin effectively reduced HCT116 cell viability by activating apoptotic responses through a Bax-dependent and p53-independent manner. The results revealed the mechanisms of cordycepin-induced apoptosis and indicated that cordycepin may be a novel therapeutic approach to cancers with wild-type Bax.

\section{Acknowledgements}

Authors would like to thank Dr Feng Zhou for statistical analysis and Dr Bert Vogelstein and Dr Quan Cheng for providing cell lines and plasmids.

\section{Funding}

The present study was supported by grants from The National Science and Technology Support Project (grant no. 2014BAI02B00), The National Natural Science Foundation of China (grant no. 81470375) and The National Science Foundation for Young Scientists of China (grant no. 31501148).

\section{Availability of data and materials}

The analyzed data sets generated during the study are available from the corresponding author on reasonable request.

\section{Authors' contributions}

SZL, RLD and XDZ designed the research; SZL, JWR and JF performed the research. SZL and RLD wrote the manuscript. SZL revised the manuscript.

\section{Ethics approval and consent to participate}

Not applicable.

\section{Patient consent for publication}

Not applicable.

\section{Competing interests}

The authors declare they have no competing interests.

\section{References}

1. Bray F, Ferlay J, Soerjomataram I, Siegel RL, Torre LA and Jemal A: Global cancer statistics 2018: GLOBOCAN estimates of incidence and mortality worldwide for 36 cancers in 185 countries. CA Cancer J Clin, 2018.

2. Kan WL, Yin C, Xu HX, Xu G, To KK, Cho CH, Rudd JA and Lin G: Antitumor effects of novel compound, guttiferone $\mathrm{K}$, on colon cancer by $\mathrm{p} 21 \mathrm{Waf} 1 / \mathrm{Cip} 1$-mediated $\mathrm{G}_{0} / \mathrm{G}_{1}$ cell cycle arrest and apoptosis. Int J Cancer 132: 707-716, 2013.

3. Siegel RL, Miller KD and Jemal A: Colorectal cancer mortality rates in adults aged 20 to 54 years in the United States, 1970-2014. JAMA 318: 572-574, 2017.

4. Evan GI and Vousden KH: Proliferation, cell cycle and apoptosis in cancer. Nature 411: 342-348, 2001.

5. Rampino N, Yamamoto H, Ionov Y, Li Y, Sawai H, Reed JC and Perucho M: Somatic frameshift mutations in the $B A X$ gene in colon cancers of the microsatellite mutator phenotype. Science 275: 967-969, 1997

6. Zhang L, Yu J, Park BH, Kinzler KW and Vogelstein B: Role of $B A X$ in the apoptotic response to anticancer agents. Science 290: 989-992, 2000.

7. Haneef J, Parvathy M, Thankayyan RS, Sithul H and Sreeharshan S: Bax translocation mediated mitochondrial apoptosis and caspase dependent photosensitizing effect of Ficus religiosa on cancer cells. PLoS One 7: e40055, 2012.

8. Zhu S, Li T, Tan J, Yan X, Zhang D, Zheng C, Chen Y, Xiang Z and Cui H: Bax is essential for death receptor-mediated apoptosis in human colon cancer cells. Cancer Biother Radiopharm 27: $577-581,2012$.

9. Li T, Liu X, Jiang L, Manfredi J, Zha S and Gu W: Loss of p53mediated cell-cycle arrest, senescence and apoptosis promotes genomic instability and premature aging. Oncotarget 7: 11838-11849, 2016

10. McCurrach ME, Connor TM, Knudson CM, Korsmeyer SJ and Lowe SW: bax-deficiency promotes drug resistance and oncogenic transformation by attenuating p53-dependent apoptosis. Proc Natl Acad Sci USA 94: 2345-2349, 1997.

11. Chittenden T, Flemington C, Houghton AB, Ebb RG, Gallo GJ, Elangovan B, Chinnadurai G and Lutz RJ: A conserved domain in $\mathrm{Bak}$, distinct from $\mathrm{BH} 1$ and $\mathrm{BH} 2$, mediates cell death and protein binding functions. EMBO J 14: 5589-5596, 1995.

12. Ferrer PE, Frederick P, Gulbis JM, Dewson G and Kluck RM: Translocation of a Bak C-terminus mutant from cytosol to mitochondria to mediate cytochrome $c$ release: Implications for Bak and Bax apoptotic function. PLoS One 7: e31510, 2012.

13. Gahl RF, He Y, Yu S and Tjandra N: Conformational rearrangements in the pro-apoptotic protein, Bax, as it inserts into mitochondria: A cellular death switch. J Biol Chem 289: 32871-32882, 2014.

14. Chandrika BB, Maney SK, Lekshmi SU, Joseph J, Seervi M, K S P and T R S: Bax deficiency mediated drug resistance can be reversed by endoplasmic reticulum stress induced death signaling. Biochem Pharmacol 79: 1589-1599, 2010.

15. Cunningham KG, Manson W, Spring FS and Hutchinson SA: Cordycepin, a metabolic product isolated from cultures of Cordyceps militaris (Linn.) link. Nature 166: 949, 1950.

16. Jagger DV, Kredich NM and Guarino AJ: Inhibition of Ehrlich mouse ascites tumor growth by cordycepin. Cancer Res 21: 216-220, 1961

17. Kondrashov A, Meijer HA, Barthet-Barateig A, Parker HN, Khurshid A, Tessier S, Sicard M, Knox AJ, Pang L and De Moor CH: Inhibition of polyadenylation reduces inflammatory gene induction. RNA 18: 2236-2250, 2012.

18. Nakamura K, Yoshikawa N, Yamaguchi Y, Kagota S, Shinozuka K and Kunitomo M: Antitumor effect of cordycepin (3'-deoxyadenosine) on mouse melanoma and lung carcinoma cells involves adenosine A3 receptor stimulation. Anticancer Res 26: 43-47, 2006.

19. Choi KS: Autophagy and cancer. Exp Mol Med 44: 109-120, 2012.

20. Tao X, Ning Y, Zhao X and Pan T: The effects of cordycepin on the cell proliferation, migration and apoptosis in human lung cancer cell lines A549 and NCI-H460. J Pharm Pharmacol 68: 901-911, 2016.

21. Chaicharoenaudomrung N, Jaroonwitchawan $T$ and Noisa $P$ : Cordycepin induces apoptotic cell death of human brain cancer through the modulation of autophagy. Toxicol In Vitro 46: 113-121, 2017. 
22. Cao HL, Liu ZJ and Chang Z: Cordycepin induces apoptosis in human bladder cancer cells via activation of $\mathrm{A} 3$ adenosine receptors. Tumour Biol 39: 1010428317706915, 2017.

23. Hwang JH, Park SJ, Ko WG, Kang SM, Lee DB, Bang J, Park BJ, Wee CB, Kim DJ, Jang IS, et al: Cordycepin induces human lung cancer cell apoptosis by inhibiting nitric oxide mediated ERK/Slug signaling pathway. Am J Cancer Res 7: 417-432, 2017.

24. An WG, Hwang SG, Trepel JB and Blagosklonny MV: Protease inhibitor-induced apoptosis: Accumulation of wt p53, p21WAF1/CIP1, and induction of apoptosis are independent markers of proteasome inhibition. Leukemia 14: 1276-1283, 2000.

25. Li SZ, Zeng F, Li J, Shu QP, Zhang HH, Xu J, Ren JW, Zhang XD, Song XM and Du RL: Nemo-like kinase (NLK) primes colorectal cancer progression by releasing the E2F1 complex from HDAC1. Cancer Lett 431: 43-53, 2018.

26. De Giorgi F, Lartigue L, Bauer MK, Schubert A, Grimm S, Hanson GT, Remington SJ, Youle RJ and Ichas F: The permeability transition pore signals apoptosis by directing Bax translocation and multimerization. FASEB J 16: 607-609, 2002.

27. Gotz C and Montenarh M: P53 and its implication in apoptosis (Review). Int J Oncol 6: 1129-1135, 1995.

28. Choisy-Rossi C, Reisdorf P and Yonish-Rouach E: Mechanisms of p53-induced apoptosis: In search of genes which are regulated during p53-mediated cell death. Toxicol Lett 102-103: 491-496, 1998.
29. Peña-Blanco A and García-Sáez AJ: Bax, Bak and beyond-mitochondrial performance in apoptosis. FEBS J 285: 416-431, 2018.

30. Yamamoto $\mathrm{T}$, Yamada A, Yoshimura $\mathrm{Y}$, Terada $\mathrm{H}$ and Shinohara Y: The mechanisms of the release of cytochrome $c$ from mitochondria revealed by proteomics analysis. Yakugaku Zasshi 132: 1099-1104, 2012 (In Japanese).

31. Tarangelo A and Dixon S: The p53-p21 pathway inhibits ferroptosis during metabolic stress. Oncotarget 9: 24572-24573, 2018.

32. Li J, Liu YY, Yang XF, Shen DF, Sun HZ, Huang KQ and Zheng HC: Effects and mechanism of STAT3 silencing on the growth and apoptosis of colorectal cancer cells. Oncol Lett 16: 5575-5582, 2018 .

33. Blankenberg FG: Apoptosis imaging: Anticancer agents in medicinal chemistry. Anticancer Agents Med Chem 9: 944-951, 2009.

34. Hardwick JM and Soane L: Multiple functions of BCL-2 family proteins. Cold Spring Harb Perspect Biol 5: a008722, 2013.

35. Zheng ZL, Qiu XH and Han RC: Identification of the genes involved in the fruiting body production and cordycepin formation of Cordyceps militaris fungus. Mycobiology 43: 37-42, 2015.

(i) () $($ This work is licensed under a Creative Commons

Attribution-NonCommercial-NoDerivatives 4.0 International (CC BY-NC-ND 4.0) License. 